\title{
Assessment of Risky Sexual Behaviors Among University Students in Kigali, Rwanda
}

\author{
Gashema Pierre $^{1,}$, Ariane Umutoni $^{2}$, Zephanie Nzeyimana ${ }^{2}$, Tafadzwa Dzinamarira ${ }^{1,2}$ \\ ${ }^{1}$ College of Medicine and Health Sciences, University of Rwanda, Kigali, Rwanda \\ ${ }^{2}$ Department of Public Health, Mount Kenya University, Kigali, Rwanda
}

Email address:

gashemapierre@gmail.com (G. Pierre)

${ }^{*}$ Corresponding author

\section{To cite this article:}

Gashema Pierre, Ariane Umutoni, Zephanie Nzeyimana, Tafadzwa Dzinamarira. Assessment of Risky Sexual Behaviors Among University Students in Kigali, Rwanda. International Journal of HIV/AIDS Prevention, Education and Behavioural Science.

Vol. 5, No. 2, 2019, pp. 141-146. doi: 10.11648/j.ijhpebs.20190502.19

Received: October 17, 2019; Accepted: November 25, 2019; Published: December 4, 2019

\begin{abstract}
Risky sexual behaviors (RSB) remain a public health concern among university students who are considered as key population for a nation's economic development. The aim of this study was to determine the proportion of sexually active students, RSB and their associated factors among students from two selected universities in Kigali. We employed a cross sectional study with data collection using a pre-tested questionnaire. IBM SPSS version 21 was employed for data analysis. Chi-square test was used to assess association between RSB and explanatory factors assuming a 95\% confidence interval, 5\% margin of error and statistical significance at $\mathrm{P}$ value less than 0.05 . A total 269 university students with almost equal representation of both males and females, $49.8 \%$ and $50.2 \%$, respectively were enrolled. Of these 269 , 68.4\% were sexually active during the period of data collection. RSB reported among university students include having multiple sexual partners with an average number of life sexual partners of 3.5, having at least one other sexual partner out of marriage (21\%), paying for sex $(16 \%)$, receiving payment for sex $(10 \%)$, having unprotected sex with only $15 \%$ of them using always using condoms with risk sexual partners and only $6 \%$ using condoms while drunk or after using drugs. RSB were more common among younger aged (between 20 and 26 years old) with peak at 23 years old, unmarried (12.6\%), widowed (50\%), cohabitating $(41.2 \%)$, prenuptial sex $(22 \%)$ groups. Findings also revealed that working students, with self-employment or professional employment, are likely to engage in sexual activity after taking drugs or alcohol. All in all, RSB are still a major problem among university students. This calls for a review of current interventions addressing sexual health among this population. There is also a need for further studies with larger sample sizes.
\end{abstract}

Keywords: Risky Sexual Behaviors, University Students, Early Sexual Debut

\section{Introduction}

Risk sexual behaviour (RSB) are becoming a central public health concern globally [1, 2]. Center of Disease Control and Prevention defined RSB as habits which can lead to sexually transmitted diseases including Human Immunodeficiency Virus (HIV) and unintended pregnancies [3]. RSB include having sex without using the condom, using unreliable methods of birth control, attending night club, having multiple sexual partners, alcohol influence, and paying for sex $[4,5]$. In divergence, having good relationship with the parents and religious convictions have been found to be a shielding measure against RSB among the youths $[4,6]$ even if an investigation of university students in Nigeria did not show any association between religion and sexual behavior [7]. A study conducted in Rwanda in 2005 and 2010 on HIV knowledge and RSB among men revealed that in 2010 , the proportion of men who had two or more sexual partners increased from $5 \%$ in 2005 to $7 \%$ in 2010 with an increase condom use prevalence among them, $75 \%$ in 2005 and $93 \%$ in 2010 [8].

Government of Rwanda has put in place and enabled numerous programs and institutions to fight against HIV/AIDS including National Program for the Fight against 
AIDS (PNLS), National AIDS commission (CNLS), District AIDS committees (CDLS) and Information, and Education and Communication (IEC). However, despite the remarkable achievement of the above stated programs among general public in Rwanda, university students who often regarded as key population in Rwandan development at high risk of being engaged in RSB [9, 10]. Subsequently the university students represent a target population of national HIV prevention program targeting to reduce the incidence of HIV infection countrywide. Possible RSB among this group of people need to be studied and acknowledged in order to incorporate right measures in already existing programs against HIV/AIDS in this population. Thus, current study aimed to explore RSB and associated factors among university students in Kigali, Rwanda.

\section{Methodology}

\subsection{Study Area}

This study was conducted in 2 universities in Kigali, one public and another one private institution. The two universities were purposively sampled from sixteen universities in Kigali.

\subsection{Study Population and Design}

This study applied an institution based cross- sectional survey study design. The target population was students enrolled in the selected universities; University of Rwanda/College of Sciences and Technology (UR/CST) and Mount Kenya University Rwanda (MKUR) during the month April 2019. These universities were purposefully selected for this study while participants were enrolled using simple random sampling.

\subsection{Data Collection Methods}

Data collection was done using a pre-tested selfadministered questionnaire comprising questions to gather participants' information on demographic characteristics, general health status, HIV- related risk behavior and HIV disease knowledge. Participant's responses were captured on paper questionnaire and entered in SPSS version 21.0 for statistical analysis.

\subsection{Statistical Analysis}

Quantitative variables are summarized by means and standard deviation (SD). Qualitative variables were summarized using frequency distribution. Chi-square test was computed to see whether there is a significant correlation between RSB and other variables. All statistical tests were concluded at a $95 \%$ confidence interval with a margin of error of 5\%. Tables and graphs were used to present results of the key findings.

\section{Results}

Current study was conducted to assess RSB among university students in Kigali, Rwanda. Presented findings from the field encompasses demographic and sexual characteristics of the study participants, RSB, and their associated factors among university students.

\subsection{Demographic Characteristics of the Study Participants}

A total of 269 participants with almost equal representation of both males and females, $49.8 \%$ and $50.2 \%$, respectively were enrolled. About $68 \%$ of the participants aged between 20.1 and 28 years old. Most of them (81\%) were doing undergraduate education with only $19 \%$ in postgraduate education. Majority of the interviewed students we unemployed with only $17 \%$ of them with professional jobs and $19 \%$ self-employed. During the period of data collection more students resided in Nyarugenge district (39\%) and Gasabo district (34\%) while less were living Kicukiro district (29\%). Only $11 \%$ were legally married, with mean age at marriage of 24.2 , while the rest were single, widowed, or cohabiting. Detailed information on participant demographic characteristics is available in table 1.

Table 1. Demographic characteristics.

\begin{tabular}{ll}
\hline Variable & Outcome, n (\%) \\
\hline Gender, n (\%) & $134(49.8)$ \\
Female & $24.1(3.9)$ \\
Age in years, mean (1SD) & \\
Education & $217(81)$ \\
Undergraduate & $52(19)$ \\
Post-graduate & \\
Source of income & $171(64)$ \\
Unemployed & $46(17)$ \\
Professional & $52(19)$ \\
Self-employed & \\
Residence & $91(34)$ \\
Gasabo & $104(39)$ \\
Nyarugenge & $71(27)$ \\
Kicukiro & \\
Marital Status & $30(11)$ \\
Married & $239(89)$ \\
Others &
\end{tabular}

\subsection{Sexual Characteristics Enrolled Students}

Apart from 11 (4.1\%) participants who did not disclose their sexual preferences, most $(88.5 \%)$ of those who did were heterosexual while $4 \%$ each were either homosexual or bisexuals. A considerable proportion (68.4\%) of the participants had ever had sex during the period of data collection with an estimate of $64.7 \%$ of them who had had sex within the last 12 months. On one hand, mean age of sexual debut was 19.2 years, with the earliest sexual debut happening at 12 years old while latest at 30 years old, on the other hand, mean age at marriage at first marriage was at 24.1 among the married and cohabitating students. Detailed information is found in table 2 . 
Table 2. Sexual characteristics among the students.

\begin{tabular}{ll}
\hline Variable & Outcome \\
\hline Sexual Preference, $\mathrm{n}(\%) \mathrm{s}$ & $238(88.5)$ \\
Heterosexual & $10(3.7)$ \\
Homosexual & $10(3.7)$ \\
Bisexual & $11(4.1)$ \\
Did not tell & $24.2(6.0)$ \\
Age at marriage in years, mean (SD) & $184(68.4)$ \\
Ever had sexual intercourse & $174(64.7)$ \\
Yes n (\%) & $19.2(3.2,12-30)$ \\
Sexually active for the last 12 months, $\mathrm{n}(\%)$ & $24.1(5.9,20-30)$ \\
Age at first sex, Mean (SD, Min-Max) & \\
Age at marriage or cohabitation, Mean (SD, & \\
Min-Max) & \\
\hline
\end{tabular}

\subsection{Risky Sexual Behaviors Among University Students}

Most common RSB among interviewed university students include having multiple sexual partners with an average number of life sexual partners of 3.5 , having at least one other sexual partners out of marriage $(21 \%)$, paying for sex $(16 \%)$, receiving payment for sex $(10 \%)$, having unprotected sex with only $15 \%$ of them using always using condoms with risk sexual partners and only $6 \%$ using condoms while drunk or after using drugs. More information about most common RSB is found in table 3 .

Table 3. RSB among university students.

\begin{tabular}{ll}
\hline Variable & Outcome \\
\hline $\begin{array}{l}\text { Number of lifetime sexual sex partners, Mean (SD, } \\
\text { Min-Max) }\end{array}$ & $3.5(3.1,1-16)$ \\
$\begin{array}{l}\text { Number of different sexual partners while married or cohabiting } \\
1 \text { sex partner }\end{array}$ & $34(12.6)$ \\
2 or more & $23(8.4)$ \\
Ever paid for sex & \\
Yes & $37(16)$ \\
Received payment for sex & \\
Yes & $24(10)$ \\
Used condom first sex & $86(40)$ \\
Yes & \\
Always use condom & $35(15)$ \\
Yes & \\
Always used condom last 12 months & $25(10)$ \\
Yes & \\
Always use condom after taking drugs/alcohol & $13(6)$ \\
\hline
\end{tabular}

\subsection{Factors Associated with RSB}

This section reports risk factors associated with ever paid for sex, engaging in unprotected sexual intercourse and having sex after drug or alcohol.

\subsection{Factors Associated with Ever Paying for Sex}

The figure 1 shows there is a weak negative correlation between age ever paying for sex. Younger aged students tend to pay for sex than their older counterparts, with the peak being at 23 years old.

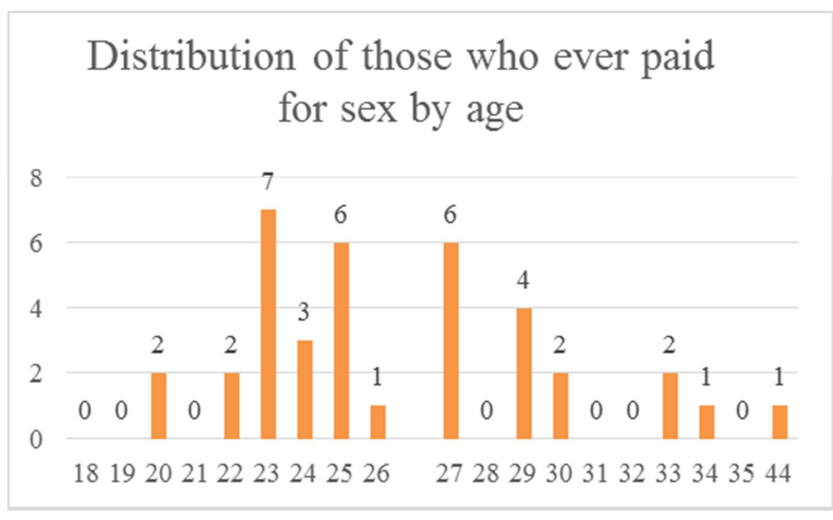

$\mathrm{P}$ value $=0.005$.

Figure 1. Ever paying for sex and participants'age.

From the table 4, there was a weak negative correlation, but statistically significant, between marital status and ever paying for sex whereby larger proportion of students ever pad for sex is among significant correlation between widowed (50\%) and cohabitating (41.2\%) groups while single and married groups presented lower proportion of paying for sex of $12.6 \%$ and $13.3 \%$, respectively.

Table 4. Factors associated with ever paying for sex.

\begin{tabular}{lllll}
\hline \multirow{2}{*}{ Variable } & \multicolumn{2}{l}{ Ever paid for sex } & \multirow{2}{*}{ N } & \multirow{2}{*}{ p-value } \\
\cline { 2 - 3 } & Yes, count (\%) & No, count (\%) & & \\
\hline Marital status & & $160(87.4)$ & 183 & \\
Single & $23(12.6)$ & $26(86.7)$ & 30 & \\
Married & $4(13.3)$ & $10(58.8)$ & 17 & 0.008 \\
Cohabitation & $7(41.2)$ & $2(50.0)$ & 4 & \\
Widowed & $2(50.0)$ & $3(75.0)$ & 4 & \\
Separated & $1(25.0)$ & & & \\
Sexual Preference & & $182(86.3)$ & 211 & \\
Heterosexual & $29(13.7)$ & $8(88.9)$ & 9 & $<0.001$ \\
Homosexual & $1(11.1)$ & $4(40)$ & 10 & \\
Bisexual & $6(60)$ & & & \\
\hline
\end{tabular}

As illustrated in the figure 2, paying for sex among the participants is very common among students who with relatively early sexual debut (ESD).

\section{Distribution of those ever paid for sex by Age of first sexual intercourse}

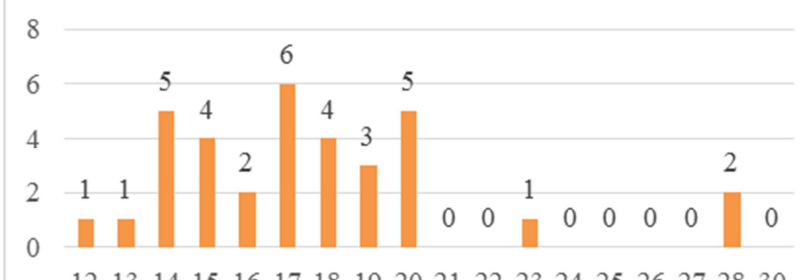

$\begin{array}{llllllllllllllllll}12 & 13 & 14 & 15 & 16 & 17 & 18 & 19 & 20 & 21 & 22 & 23 & 24 & 25 & 26 & 27 & 28 & 30\end{array}$

$P$ value $=0.003$.

Figure 2. Distribution of those ever paid for sex by Age at sexual debut. 


\subsection{Factors Associated with Having Sex After Drug or Alcohol}

The table 4, shows that professional and self-employed university students are more likely to engage in sex after drug or alcohol use compared to their unemployed counterparts. Apart from this factor, current data have not shown any other factor significantly associated with risky sexual behavior of having sex after drug or alcohol.

Table 5. Factors associated with having sex after drug or alcohol.

\begin{tabular}{|c|c|c|c|c|c|c|}
\hline \multirow{2}{*}{ Factors } & \multicolumn{4}{|c|}{ Sex after drug or alcohol } & \multirow{2}{*}{$\mathbf{N}$} & \multirow{2}{*}{ P value } \\
\hline & Never & Rarely & Sometimes & Always & & \\
\hline \multicolumn{7}{|c|}{ Source of financial income } \\
\hline Unemployed & $115(74.7)$ & $25(16.2)$ & $13(8.4)$ & $1(0.6)$ & 154 & \multirow{4}{*}{$<0.001$} \\
\hline Professional & $23(54.8)$ & $8(19)$ & $7(16.7)$ & $4(9.5)$ & 42 & \\
\hline Self-employed & $20(40)$ & $16(12)$ & $12(24)$ & $2(4)$ & 50 & \\
\hline Total & $158(64)$ & $49(19.9)$ & $32(13)$ & $7(2.8)$ & 246 & \\
\hline
\end{tabular}

\section{Discussion}

The proportion of sexually active students (68.4\%) and the alarming rate of early sexual debut (ESD) (more than 1 in 10) are baseline indicators to justify the great need for sexual health education among this key population of the country to reduce reported RSB which have not yet attracted significant public health intervention in Rwanda. Although there is no set national health priority about RSB, failure to inclusively avail these services for this group of people, who are considered as key country' economy developers [11], can lead to total deviation of all 17 Rwandan targets to achieving SDGs [11], mainly goals focusing on human capital development and ensuring good health for all [12].

Current rate $(68.4 \%)$ of sexually active university students in Kigali Rwanda is slightly lower that reported among Washington University students of 76.4 in 2017 but comparable to that reported in 2016 among the same students of $67.7 \%$ [13] and in a Nigerian study of $58 \%$ of 236 of the respondents [10]. However, it is far higher than that reported in Ethiopia among undergraduate students of $28 \%$ in Haramaya University [5] and Iranian study of $15.1 \%$ [13](14). Current mean age of sexual debut (19.2, 12-30 years old) is higher that reported in the Nigerian study where age at sexual debut was 16 years old, varying from 9 to 21 years old [10]. Regarding current estimate $(64.7 \%)$ of the students who had had sex within the last 12 months preceding data collection is higher than that in the Ethiopian study of $50.9 \%$ [5]. Current early sexual debut (ESD) $(11 \%)$ is less compared to that in the Iranian study of $24 \%$ [14] (14). The same sexual behaviors have been reported in several other studies including an Iranian study [14] and Botswanan study. However, the rate of consistent condom users was far less $(5.7 \%)$ than in the current report $(15 \%)$. This complexed with intergenerational sex, justifies high STI prevalence among Youth in Botswana [15]. Current rate of condom use (15\%) far less than that in the US among Washington University students of $81.3 \%$ [13], Iran of $40.6 \%$, and Ethiopia of $32.7 \%$ [14] but comparable to that reported in Nigeria of $18 \%$ [10]. Apparent disparities in findings across different countries can be attributed to varying levels of geographical differences, culture, knowledge and awareness of the population about sexually transmitted diseases and their associated life consequences.

Current findings suggest a great need to avail sexual health services in all higher learning institutions and continuous sex education programs along with a well-structured plan to assess success of the program among university students. Despite apparently high ESD rate (more than 1 in 10) among university students, this rate may be much higher in the general population, especially in urban areas of the country including Kigali city. Thus, the need to establish population based ESD rate. Better quality contraceptive methods like high quality condoms which boost sexual pleasure or with minimal side effects, and easily administered or non-invasive methods to prevent sexually transmitted diseases and unwanted pregnancies should all be readily accessible by everyone.

All in all, although this study has failed to find out the association between demographic characteristics and sexual behaviors with having unprotected sex among university students, RSB remain a major public concern among this population group. It is also highly recommended to assess reasons of ESD and STIs using larger sample size and from various universities across the country. This will guide sexual health promotion programs targeting most affected groups of university students.

\section{Conclusion}

Current study has found that of $68.4 \%$ of university students are sexually active and that, RSB include: having multiple sex partners, at least one extra marriage sex partner, sex for money, unprotected sex, and sex under influence of drug or alcohol. current findings underscore the need for enhanced and tailored health education to university students on RSB especially those aged 26 years and younger, unmarried, widowed, cohabitating, employed, and those who had early sexual debut as these groups of people are the most affected by RSB. We recommend further studies that including mixed approach in order to explore both risk sexual behavior and STIs, early sexual debut using larger sample size and from various universities across the country 


\section{Limitations}

This study was a cross-sectional nature of study design might have been biased with subjective responses from students. The cross-sectional nature of this study did not clearly identify a causality relationship of independent variables and the dependent variable. However, this study identified risk factors and predictors which may serve as a basis for future research on sexual debut and HIV associated risk perception and behavior among university students. There is a need for a larger substantive study with a more heterogeneous study population; however, this study still provides useful baseline data.

\section{List of Abbreviations}

AIDS: Acquired immune deficiency syndrome HIV: Human immunodeficiency virus

RSB: Risk sexual behaviors

\section{Declarations}

\subsection{Ethics Approval and Consent to Participate}

This study was approved by the University of Rwanda, College of Medicine and Health Sciences Institutional Review Board. Permission was obtained from the Students' Guild Presidents at the tertiary institutions prior to conducting this study. All study participants also signed an informed consent prior to participating in the study.

\subsection{Consent for Publication}

Not applicable.

\subsection{Availability of Data and Materials}

If needed the raw data used for this article is available upon reasonable request in writing to the corresponding author.

\subsection{Competing Interests}

The authors declare that they have no competing interests.

\subsection{Funding}

No funding was received for this study.

\subsection{Authors' Contributions}

GP and AU conceptualized the study and prepared the draft proposal. $\mathrm{ZN}$ contributed to the development of the background and planned the output of the research as well as the design of the study. GP and AU collected data. ZN conducted data analysis. GP prepared the manuscript, $\mathrm{ZN}$ and TD critically reviewed it. All authors (GP, AU, ZN, and TD) contributed to the reviewed draft version of the manuscript and approved the final version.

\section{References}

[1] Amaranganie U, Perera P, Abeysena C. Prevalence and associated factors of risky sexual behaviors among undergraduate students in state universities of Western Province in Sri Lanka: a descriptive cross sectional study. 2018; 1-10. Available from: https://www.ncbi.nlm.nih.gov/pubmed/29866189.

[2] WHO. Casting light on old shadows: ending sexually transmitted infection epidemics as public health concerns by 2030: advocacy brief. World Heal Organ Geneva [Internet]. 2017; $10 \quad$ (12): $1-8$. Available from: https://www.who.int/reproductivehealth/publications/rtis/endi ng-stis-advocacy-brief/en/.

[3] Cdc. Sexual Risk Behaviors Can Lead to HIV, STDS, \&amp; Teen Pregnancy | Adolescent and School Health | CDC [Internet]. 2018 [cited 2019 Aug 12]. Available from: https://www.cdc.gov/healthyyouth/sexualbehaviors/index.htm.

[4] Ware E, Tura G, Alemu T, Andarge E. Disparities in risky sexual behavior among khat chewer and non- chewer college students in Southern Ethiopia: a comparative cross-sectional study. 2018; 1-12. Available from: https://bmcpublichealth.biomedcentral.com/articles/10.1186/s 12889-018-5405-xhttps://doi.org/10.1186/s12889-018-5405-x.

[5] Tariku Dingeta, Lemessa Oljira NA. Patterns of sexual risk behavior among undergraduate university students in Ethiopia: a cross-sectional study. Pan African Med Journal [Internet]. 2019; I: 1-7. Available from: https://www.panafrican-medjournal.com/content/article/12/33/full/.

[6] Peltzer K, Pengpid S, Peltzer K, Pengpid S. Early Sexual Debut and Associated Factors among In-school Adolescents in Six La Iniciación Sexual a Edades Tempranas y Sus Factores Asociados entre los Adoles- centes de Escuelas en Seis Países del Caribe. 2015; 64 (4). Available from: https://www.ncbi.nlm.nih.gov/pmc/articles/PMC4909066/http s://doi.org/10.7727/wimj.2014.025.

[7] Omoteso BA. A Study of the Sexual Behaviour of University Undergraduate Students in Southwestern Nigeria. 2006; 12 (2): 129-33. Available from: http://citeseerx.ist.psu.edu/viewdoc/download?doi=10.1.1.476 $.493 \&$ rep=rep1\&type=pdfhttps://doi.org/10.1080/09718923.2 $006.11978380 /$.

[8] Chitou B, Boer K, Hedt-gauthier B, Gupta N. sex workers in Rwanda. Int J STD AIDS [Internet]. 2018; 28 (11): 1082-9. Available from: https://www.ncbi.nlm.nih.gov/pmc/articles/PMC6512058/pdf/ 10.1177_0956462418817050.pdfhttps://doi.org/10.1177/0956 $462416 \overline{688137 .}$

[9] Shiferaw Y, Alemu A, Assefa A, Tesfaye B, Gibermedhin E, Amare M. Perception of risk of HIV and sexual risk behaviors among University students: implication for planning interventions. BMC Res Notes [Internet]. 2014; Available from: https://www.ncbi.nlm.nih.gov/pmc/articles/PMC3974211/https:// doi.org/10.1186/1756-0500-7-162.

[10] Saad A, Awaisu A, Rampal L, Sabitu K, Lawal A, Gwarzo U. HIVrelated sexual risk behaviors among university students in Northern Nigeria. Int J Infect Dis [Internet]. 2014; 21: 108. Available from: https://www.ijidonline.com/article/S1201-9712(14)007103/pdfhttps://doi.org/10.1016/j.jijid.2014.03.651. 
[11] MINECOFIN RWANDA. Your Guide to the Sustainable Development Goals (SDGs) in Rwanda. 2015; Available from: http://www.minecofin.gov.rw/fileadmin/user_upload/Guide t o_SDGs_in_Rwanda_ENG.pdf.

[12] Republic of Rwanda. 2019 Rwanda Voluntary national review of SDGs. 2019; (June). Available from: https://sustainabledevelopment.un.org/content/documents/234 32Rwanda_VNR_Document_Final.pdf.

[13] Ella Chochrek. 2017 sex survey statistics reveal students' sex habits | Student Life [Internet]. 2017 [cited 2019 Aug 2]. Available from: http://www.studlife.com/special-issues/sexissue/sex-issue-2017/2017/02/13/2017-sex-survey-statisticsreveal-students-sex-habits/.
[14] Hedayati-Moghaddam MR, Eftekharzadeh-Mashhadi I, Fathimoghadam F, Pourafzali SJ. Sexual and Reproductive Behaviors among Undergraduate University Students in Mashhad, a City in Northeast of Iran. J Reprod Infertil [Internet]. 2015; 16 (1): 43-8. Available from: http://www.ncbi.nlm.nih.gov/pubmed/25717435\%0Ahttp://w ww.pubmedcentral.nih.gov/articlerender.fcgi?artid=PMC4322 181.

[15] Hoque M, Ntsipe T, Mokgatle-Nthabu M. Sexual Practices among University Students in Botswana. Gend Behav [Internet]. 2012; 10 (2): 4645. Available from: https://www.tandfonline.com/doi/full/10.1080/17290376.2013 .869649 https://doi.org/10.1080/17290376.2013.869649. 